ANKARAD / A.JARS

ANKARA ANADOLU VE RUMELI ARAŞTIRMALARI DERGISI

ANKARA'S JOURNAL OF ANATOLIA AND RUMELIA STUDIES

ANKARAD, 2021; 2(4): 407-424 $\quad$ ankaradergisi06 $a$ gmail.com

\begin{tabular}{l|l} 
e-ISSN: $2717-9052$ & DOI: 10.53838 /ankarad.997809
\end{tabular}

Araştırma Makalesi

\title{
YAZITLAR IȘIĞINDA ANADOLULU KADIN HEKİMLER VE EBELER
}

\section{Ayşen SínA*}

Öz: Hastalkklanın sağaltılmasına yönelik uygulamalanı tarihsel geçmişi, hiç şüphesiz insanlık tarihi kadar eskidir. Eskiçağlardan günümüze gelen mitoslar, yaşam ile ölümün gizemlerini yalnızca kadınların bildiğini, bu doğrultuda da büyülï̈ şifa sanatının inceliklerine vakıf olduklarına işaret etmektedir. Oysa tüm dünyada, 19. ve 20. yüzyıl kadınlanımın tıp fakültelerine kabul edilme mücadelesinin aksine, antik Yunanistan'da kadınlar MÖ 4. ve Roma'da MÖ 1. yüzyıldan itibaren hekimlik sanatını uygulama özgürlüğüne kavuşmuşlardı. Başlangıçta yetenek gerektiren mesleklere pek uygun görülmeyen kadınların, kadim zamandan bu yana geleneksel yöntemlerle hastalıkları iyileştirdikleri ve aym şekilde doğumlara yardımcı oldukları bilinmektedir. İyileştirme rollerindeki şifacı kadınlar için kullanılan ve onların bireysel rollerini ifade eden terimler dikkate alındığında, Yunanistan'da "maia" ile "iatrikê", Roma'da "obstetrix" ve "medica" veya "iatrina" meslekleri arasında bir ayrım olduğunu görmekteyiz. Bu çalışma, şifacı kadının kendi bağlamı içinde, iki mesleğin uygulayıcılarının eğitimi, nitelikleri, görevleri ve toplumsal statülerini araştırmaktadır. Ortaya konan kanıtlar, tüm şifacı kadınların toplumlarının sinılarını zorlamadıkların, hatta mesleklerinin uzmanı olarak saygı gördüklerini ve yetkin olduklarını göstermektedir.

Anahtar Kelimeler: Hastalıkların Sağaltımı, Hekimlik Sanatı, Eli Hekimliğe Yatkın Kadınlar, Hayat Veren Ebeler, Mezar Taşlarında Ölümsüzleșen Kadınlar.

\section{ANATOLIAN FEMALE PHYSICIANS AND MIDWIVES IN THE LIGHT OF INSCRIPTIONS}

Abstract: The historical background of practices for curing diseases is without a doubt as old as history. The myths from ancient times to the present point out that only women knew the mysteries

* Prof. Dr. Tekirdağ Namı Kemal Üniversitesi Fen Edebiyat Fakültesi Tarih Bölümü Eskiçağ Tarihi asina@nku.edu.tr, ORCID: 0000-0002-5301-5973. 
Sina, A. (2021). Yazıtlar Ișı̆ı̆ında Anadolulu Kadın Hekimler ve Ebeler. ANKARAD, 2(4), 407-424.

of life and death, and in this direction, they were aware of the subtleties of the art of magical healing. However, all around the world, contrary to the struggles of 19th and 20th century women to be admitted to medical schools, women in ancient Greece had the freedom to practice the art of medicine since the 4 th century $\mathrm{BC}$ and in Rome from the 1st century BC. In the beginning, it was known that women, who were not very suitable for professions that required talent, had been healing diseases with traditional methods since ancient times and also assisted in childbirth. We see a distinction between the professions of "maia" and "iatrikê" in Greece, "obstetrix" and "medica" or "iatrina" in Rome, the terms used for healer women in healing roles and expressing their individual roles. This study researches the education, qualifications, duties, and social status of practitioners of the two professions within the context of the healer women. Evidences show that not all healer women pushed the boundaries of their society, but are even respected and competent as professionals in their profession.

Key Words: Treatment of Diseases, The Art of Medicine, Women who are prone to be Physicians, Life-Giving Midwives, Women Immortalized on Gravestones.

Extended Abstract: General references and representations of female medical practitioners in the Hellenistic, and Roman imperial periods are also associated with literary culture. Although it gives a limited view of social structures, epigraphic materials about female physicians and midwives from Anatolia, especially tomb inscriptions, show that husbands and wives, fathers and daughters participated in the same professions. Moreover, families also pointed out that the profession of medicine, which was thought to be specific to men, can be passed on to their daughters or spouses. Every female physician treated not only pregnancy and obstetrics or women and young children. In the beginning, although female physicians treated women, they treated men as well. This shows that especially the inscriptions found in Anatolia in the 1st and 2nd centuries $\mathrm{AD}$, a woman with a certain background was an expert in her profession as we see in the tomb inscriptions of Antiochis and Domnina, and gained a great reputation in their society for protecting their homeland (from diseases). It is stated that the deaths of these valuable female physicians are a loss not only for their husbands/family but also for their hometowns. Panthia's epitaph, on the other hand, gaining her reputation as a healer as a "saviour" in her community proves that she was a physician equivalent to her husband and her own father, who were both physicians. Furthermore, the inscriptions also demonstrate familial occupational interactions, showing that educating parents in their own profession is the best proven form of knowledge and skill transfer. Alongside the evidence 
Sina, A. (2021). Yazıtlar Ișı̆ı̆ında Anadolulu Kadın Hekimler ve Ebeler. ANKARAD, 2(4), 407-424.

for their healing responsibilities at home, female physicians, in addition to being students of their fathers or mothers, actually testify to an ongoing tradition. The Late Classical and Hellenistic periods showed that healer women received an education that developed concurrently with that of male healers. Moreover, the terminology used in the inscriptions also indicates that healer women did not suffer gender discrimination in their professional roles. These periods showed that attitudes towards women, in particular, women physicians and midwives, changed and they were generally accepted as respected members of the society. Even if it was presumed that female physicians performed a male profession, there were certainly varying levels of acceptance from society to society, but no record of opposition to them was found, possibly due to their low number and the quality of the evidence. On the contrary, from the inscriptions found in Anatolia, we can say that healer women are welcomed in their societies with a high level of prestige, but it is also a fact that this attitude has changed depending on the geographical area and time. In line with what the tomb inscriptions about female physicians and midwives have presented to us, it would not be wrong to think that many more healer women were honored in these periods.

\section{Giriş}

Kadın şifacıların yaşamöyküleri ve günlük yaşantılarına dair iz bulunmamasına rağmen, mevcut belgeler eski dönemlerden bașlayarak şifacı kadınların toplumlarına katkılarının kamuoyu tarafindan da tanındığını göstermektedir. Olasılıkla bilginin, örnekler görerek ya da dilden dile aktarılarak öğrenildiği hekimlik mesleğindeki kadınlar hakkında veya kadınlara tıbbi bir bakıș açısı sunan bilgiler, tıp yazarlanı Soranus, Galenos ve diğerlerinin eserlerinden oluşan anlatılardan ve mezar yazıtlan gibi epigrafik materyallerle desteklenmiș diğer Yunan ve Latin yazarlarının eserlerinden gelmektedir. Anadolulu kadın hekimlerin mezar yazıtlanı, bu sıra dışı hizmetlerde, erkeklerle aynı șekilde onurlandırıldıklarını ve tıbbi çalışmalarda meslektaş olarak kabul gördüklerini; edebi ve tıp konusundaki eserlerde adlarının anılması ve hatta eserlerinde onlara atıfta bulunmalarından anlaşılmaktadır. $\mathrm{Bu}$ nedenle, hiçbir zaman çok fazla kadın hekim olmamasına rağmen, Helenistik ve Roma dönemlerinde, kadın hekimlerin mesleklerini uygulamaları yönünde pek de aşılmaz bir engel görünmüyor. Ayrıca kısıtlı bilgiye rağmen tüm yazılı kaynaklar, hekimlik mesleğinde kadınların varlığının özel olarak bahsedilmeyi gerektiren istisnai bir olgu olmadığını gösterdikleri için de son derece önemlidirler.

Tüm dünya toplumlarında hastalıkların sağaltılması, gündelik yaşayış ve devlet yönetim biçimleriyle yakından ilişsilidir. Dinin egemen olduğu 
Sina, A. (2021). Yazıtlar Ișı̆ı̆ında Anadolulu Kadın Hekimler ve Ebeler. ANKARAD, 2(4), 407-424.

toplumlarda dualar ve büyülerle, savaşçı toplumlarda cerrahi uygulamalarla ve tarım toplumlarında ise bitkilerle tedavi yönetmeleri kadim zamanlardan bugüne uygulanagelmiştir. Batı Anadolu, Yunanistan ve Ege adalarında MÖ 7. yüzyıldan başlayarak Doğu uygarlıklarının etkisiyle büyük bir gelişme gösteren Yunan Uygarlığı, tıp alanında üç dönem geçirmiştir. Mitolojik dönem, filozof hekimler dönemi ve Hipokrates ile başlayan Hipokratik dönem. Mitolojik anlatılar içinde yer alan şifacı kadınlar, hastalıkların sağaltılmasında bitkileri kullanmaları ve bunlara yükledikleri büyüsel anlamlar konusunda derin bilgiye sahiptiler. $\mathrm{Bu}$ dönem insanları hastalık etkenlerinin doğadan kaynaklandığını, dolayısıyla tedavisinin de doğada bulunduğundan hareketle bitkisel yöntemleri kullanmışlardır. Toplumsal rollerin belirlediği görev dağılımında toprakla uğraşmak kadının sorumluluğundaydı, bu nedenle toprakla doğrudan ilişki kadınların bitkiler konusundaki bilgi hazinesini geliştirmiş ve hastalıkların sağaltılmasında bitkilerin şifa verme gücünü kullanmışlardı.

Mitoslardaki şifa dağıtıcı kadınların başında, çocukları ve kadınları koruyup gözeten Demeter, hasta dişleri ve gözleri sağaltan Persephone, kısırlık sorunlara çare olan Genetyllis, çocuk hastalıkları uzmanı Hekate, körlüğü iyileştiren Athena, uzmanlık alanlan zehirler ve onların panzehirleri olan Medeia ile Kirke, cerrah Leto ve tanrısal âlemin ebesi Eiliethyia say1labilir.

Hekimliğin bilimsel temellerini atmasıyla ve hekimlik uygulamalarına ilişkin anlatımlarıyla tanınan Koslu Hippokrates (MÖ ca. 460-370) ile birlikte, neredeyse tamamı erkek olan edebi kaynakların yazarlarının, kadın hekimler konusundaki görüşleri son derece çarpıcıdır. Hippokrates'in yemin metninde kadın hekimlerin adlan da sayılır:

"Hekim Apollon' 'u, Asklepios' 'u, Hygieia, Panakeia ve bütün tanrı ve tanrıçalar adına yemin ederim. Onları tanık ve şahit tutarım $k i$, bu andım ve verdiğim sözü gücüm kuvvetim yettiği kadar yerine getireceğim". ${ }^{1}$

Yazarın, Corpus Hippocraticum (Hippokrates Külliyatı) olarak bilinen hekimlik konularını içeren koleksiyonu 60 kadar incelemeden oluşur. Bu koleksiyon, Kos Adası'nda tanrı Askelpios'un şifa dağıtan tapınağıyla bağlantılı Hippokratesçi tıp okulu kütüphanesinde bulunan yapıtlardır. Söz konusu eser anatomi, farmakoloji, embriyoloji, epidemiyoloji ve genel sağlık konularında incelemeler içerir. Hippokrates'e göre bir hekim şöyle olmalıdır:

1 Hippokr., The Hippocratic Oath: Loeb 298-299= 4.39 Littré. F. Rosenthal, "An ancient commentary on the Hippocratic oath", Bulletin of the History of Medicine, 30, 1956, s. 52 87. 
Sina, A. (2021). Yazıtlar Ișı̆ı̆ında Anadolulu Kadın Hekimler ve Ebeler. ANKARAD, 2(4), 407-424.

"Sağlkklı görünmeli, doğanın izin verdiğince gürbüz olmall; çünkü genel kanı odur ki, kendi vücuduna bakmayan, basskalarına da bakamaz. Temiz olmall, iyi görünmeli, hoş kokulu merhemler sürünmelidir. Görünüşü ciddi olmal ama sert olmamalıdır; sertlik kibir ve kabalık olarak algılanır. Kontrolsüz gülen ve aşırı neşeli olan kişi ise bayağı bulunur, bayăğllktan kaçınmalıdır."2

Platon'un (MÖ 429-347) Theaitetos başlıklı eserinde ebelik mesleği konusunda șunları yazar:

"Ebelik sanatınin bütün gelenek ve göreneklerini hattrlayver; sana anlatmak istediklerimi kolayca kavrayacaksin. Daha gebe kalabilecek ve doğuracak hiçbir kadın başkaların doğurtmak için bu mesleğe giremez; bunu ancak artık doğuramayacaklar yapar. Ebelik sanatına önayak olan, söylendiğine göre, Artemis imiş; kendisi hiç doğurmadığı için doğum esnasinda görülecek işlere nezaret etmeyi himayesine almış; görgü olmadan bir sanatı ögrenmek mümkün değildir; işte, insan doğasinın bu zaafinı göz önünde tutarak tamamıyla kisır olanlara ebeliği yasak ediyordu. Sonra gebelik var mi yok mu bunu başkalarıyla kiyaslanırsa, ebelerin daha iyi bileceği de gerçek ve zorunludur. Ebeler ilaçlarlyla, sihirleriyle ağrlları uyarmaya veya arzuya göre yatıştırmaya ve güç doğumlarda doğumu sağlamaya, gerek görülüyorsa çocuk düşürmeye yetkidirler. Ayrıca en iyi çocuklart meydana getirmek için hangi kadınin hangi erkekle birleşmesi gerektiğini çok iyi bilirler". ${ }^{3}$ Devlet başlık1 eserinde ise "Bir devletin temelini atarken, yaradilışı ayrllk ve aynllkların kesin bu ayrilık ve aynulıkların işlerde tam bir karşıllı̆g olacă̆ın düşünmemiştik. Nitekim biz, eli hekimliğe yatkın bir adamla kafası hekimliğe yatkın bir adamı ayn yaradıllşsta saymıştık" ${ }^{4}$

Aristoteles (İ̈ 384) zamanına gelindiğinde Delphoi rahibelerinin şifacılık sanatları çoktan erkeklere geçmişti. Bununla birlikte Aristoteles'in "yardımcım" dediği karısı Pythias bitki ve hayvan yaşamını incelemiş ve hatta gözlemlerini bir kitapta toplamışt. Ama Pythias özellikle doku araștırmaları ve üremeyle ilgilenmiști. ${ }^{5}$

Misır İskenderiye'de tıbbın önde gelen kurucularından biri olan Khalkedonlu (Kadıköy) hekim Herophilos (MÖ 320-260), 19. yüzyıldan önce insan kadavralarını inceleyen çok az hekimden biri olup üreme organları, göz, beyin üzerine incelemelerinin yanı sıra kadın anatomisi bilgisine önemli katkılarda bulunmuștur. Overleri ve fallop tüplerini tanımlayan ilk hekim olan Herophilos'un günümüze fragmanları kalan Maieutikon başlıklı eseri, doğum ve jinekoloji üzerine bilinen en eski çalışmadır. Antik Yunan ve Roma dünyasının olasılıkla en önemli

\footnotetext{
${ }^{2}$ Ralph Jackson, Roma İmparatorluğu'nda Doktorlar ve Hastallklar (Çev.: Ş. Mumcu) İstanbul, Homer Kitabevi 1999, s.54.

${ }^{3}$ Plat. Theait. $149 \mathrm{~b}-\mathrm{d}$.

${ }^{4}$ Plat. Rep. $454 \mathrm{~d} 2$.

${ }^{5}$ Diog. Laert. V. 1.
} 
Sina, A. (2021). Yazıtlar Ișı̆ı̆ında Anadolulu Kadın Hekimler ve Ebeler. ANKARAD, 2(4), 407-424.

jinekoloğu Ephesoslu Soranus (MÖ 98-138) idi. Dört kitaptan oluşan Gynaeciorum Commentarii bașlıklı eserinde kadın anatomisini konu almıştır. Ebelere yönelik ayrıntılı açıklamaları, yakın zamana kadar ders kitabı olarak görev yapmıştır. ${ }^{6}$ Martialis' in (MS 38-104) epigramları ${ }^{7}$ ve Iuvenalis'in (MS 55-140) yergileri ${ }^{8}$ (satir), "yüksek sosyeteye" hizmet eden kadın hekim, ebe ve bu konularda yazan kadınlara ilişkin göndermelerle doludur.

Yaşlı Plinius (MS 23-79) Doğa Tarihi başlıklı eserinde, çoğunlukla görünüşte ebelerin eğitimi için obsettrik ve jinekoloji konularıyla ilgili incelemeler yazan birkaç kadına atıfta bulunur. Bunlardan ilki post partum sonrası üçüncü ve dördüncü günlerde meydana gelebilecek ateş ve sorunlu adet dönemleri için bir tedavi öneren ebe Sotira'dır. Plinius'a göre, jinekolojinin dışında diğer alanlarda gösterdiği tıbbi yetkinliği için övülen Sotira, kadınların iyileşme eylemleri gerçekleștirebilecekleri fikrini desteklemektedir. ${ }^{9}$ Plinius'un söz ettiği bir diğer kadın hekim, Lemnos Adası'ndan gelen bir ebe ve aynı zamanda şair olan Salpe'dir. Adı geçen kadın hekimin, gündelik hayatta sıklıkla kullanılan malzemelerle afrodizyaklar hazırladığı, zayıf gözleri tedavi ettiği, fazla kılları giderdiği ve hatta köpek havlamasını durdurabildiği ve ayrıca kadın hastalıklan hakkında yazdığı belirtilmektedir. ${ }^{10}$ Plinius'un yazdıkları doğrultusunda, istisnalar olsa da uzman olsun olmasın, kadın hekimlerin çoğunun daha ziyade kadın hastalıklarını tedavi ettiklerini söyleyebiliriz. Ayrıca, yazarın andığı diğer iki kadın MS 2. yüzyılda yaşayan Lais ve Elephantis'tir. Roma'da menstrüel sorunlar üzerine yazılar yazmışlar, ancak kürtaj yapma, doğurganlığa veya kısırlığa neden olan etmenler konusunda bakış açılarıyla birbirlerinden farklılık göstermişlerdir. ${ }^{11}$ Plinius, Lais ve Elephantis'i kürtaj ve ateş konusunda en yetkin uzmanlar olarak tanımlasa da söylediklerine inanmamanın daha iyi olacağını söyler. ${ }^{12}$ Ayrıca Plinius'un söz ettiği kadın hekimlerden bir diğeri de kürtaj, menstrüel sorunlar, k1sırlık, düşük yapma ve genel olarak kadın hastalıklarının önlenmesi üzerine yazan Thebaili Olympias’tır (MS yaklaşık 25). ${ }^{13}$

\footnotetext{
${ }^{6}$ Soran. Gynec. I.1-6.

${ }^{7}$ Mart. Epigr. I.47, V.9, X.35.

${ }^{8}$ Iven., III.62, 77, V.103, VI. 581, XI. 51.

${ }^{9}$ Plin. NH XXIII.83, XXVIII.77.

${ }^{10}$ Age, XXVIII.80; XXVIII.18; XXXII..47;51.

${ }^{11}$ Age, XXVIII.23.

${ }^{12}$ Age, XXVIII.81.

${ }^{13}$ Age, XX.84.
} 
Sina, A. (2021). Yazıtlar Ișı̆ı̆ında Anadolulu Kadın Hekimler ve Ebeler. ANKARAD, 2(4), 407-424.

Modern çağ tıbbını derinden etkileyen Bergamalı hekim Galenos (AD 129c.200), imparator Marcus Aurelius ile oğlu Commodus'un ve ardından da Septimius Severus'un hekimiydi. Bu üretken hekimin sağlık ve hastalıkla ilgili her dalı kapsayan yapıtlanı arasında jinekolojiye verdiği özel önem ve ebelerin doğumlardaki rolleri de anlamlı bir yer tutmaktadır. Antikçağın en ünlü jinekoloji ve obstetrik yazan olan Soranus'a göre, ebe olmak isteyenlerin olmazsa olmazı okuryazar olmalarıydı. Kadın şifacıların varlığını onaylayan ve eğitimlerine destek veren hekim yazar, "halkın, kadınlarda erkeklerdekine benzemeyen garip hastalıklar olduğunda genellikle ebelere başvurduğunu" söyler. ${ }^{14}$

Eşsiz kadın hekim Metrodora (MS 1. yüzyıl), tıp literatüründe bir kadın tarafından yazılmıș en eski metin kabul edilen "Kadın Hastalıklarl ve Tedavileri" (Peri ton gynaikeion pathon tes metras) başlıklı eserin yazarıdır. İki cilt 63 bölümden oluşan ve mide, böbrekler, rahim konularının ön plana çıktığı kitabı, eski Yunan ve Roma dönemlerinde ve hatta Ortaçă̆ Avrupası'nda da diğer tıp yazarları tarafindan sıcça referans alınmıștır. ${ }^{15}$ Metrodora'nın eserinde Hipokrates'in (MÖ 460-370) çalışmalarından doğrudan alıntılar yapması dikkat çekicidir. Diğer yandan Metrodora, eserinde etiolojik ve semptomatik açıdan, yani hastalıkların sebebine ve sonuçlarına dair ileri görüşlü saptamalarıla ve kendine özgü fikirleriyle alanında çığır açmıştır. Yaşadığı dönemde diğer alanların aksine, ebelik alanının kapsamında olduğu düşünülen kadın hastalıkları ve doğumla ilgili uzmanlaşmasına göz yumulan Metrodora'nın engin bir pratik bilgiye sahip olduğu söz konusu eserinin tam anlamıyla ilk alfabetik tıp ansiklopedisi olmasından anlaşılmaktadır. Adını anmadan geçmeyeceğimiz bir diğer kadın tıp yazan Kleopatra'dır. Kosmetika başlıklı eseri Galenos tarafından anılmaktadır. ${ }^{16}$

\section{Kadın Hekimler}

Epigrafik kaynaklar, kadim tıpta kadınların meslekleri ve kariyerleri hakkında değerli bilgiler sağlamaktadır. Toplumun daha alt sınıflarında çalışan kadın hekimler, erkek meslektaşları gibi, mezar yazıtlarında ölümsüzleștirilmişlerdir. Bu kadın hekimlerin çoğu Yunan kökenli olup adları Yunan-Latin kaynaklıydı. ${ }^{17}$ Kadınların deneysel dünyasının

\footnotetext{
${ }^{14}$ Soran. age, I.3.

${ }^{15}$ Holt Parker, "Women Doctors in Greece, Rome, and the Byzantine Empire", in Lilian R. Furst (ed.), Women Healers and Physicians. Climbing a Long Hill (Lexington: University Press of Kentucky), 1997, s.138.

${ }^{16}$ Gal. Nat. Fac. XII.403. XV.405.17.

${ }^{17}$ Sarah B. Pomeroy, "Plato and the Female Physician (Republic 454d2)", The American Journal of Philology, 99 (4), 1978, s.496-500. 499.
} 
Sina, A. (2021). Yazıtlar Ișı̆ı̆ında Anadolulu Kadın Hekimler ve Ebeler. ANKARAD, 2(4), 407-424.

genellikle erkeklerin gözünden temsil edildiği tarihsel olarak doğrulanamayan edebi kaynakların aksine, mezar yazıtları, ilgili kişi hakkında doğrudan ve nesnel kanıtlar sunar. Bununla birlikte birçok Yunan ve Roma mezar yazıtı, bu kadınları belirli bir zaman ve bağlamda konumlandırmayı olanaksız kılan bir addan yalnızca biraz daha fazlasını ortaya koymaktadir.

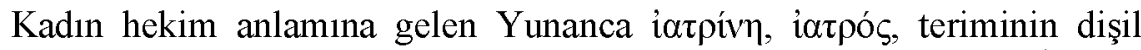
formudur ve "iyileştiren kişi" veya "hekim / cerrah" anlamına gelir. İlk kez Homeros'un Illyada destanında ve tarihçi Herodotos'ta karşımıza çıkar. ${ }^{18}$ Eril biçimi i $\alpha \tau$ ós Herodotos ve Platon'da da belirtildiği gibi "hekimlik sanatında yetenekli" anlamına da gelebilir. ${ }^{19}$ Dişil formu iatpím terimi ise yazıtlarda edebi kaynaklardan daha yaygın kullanılmaktadır. Dolayısıyla Yunan dilinin kendisinin kadın hekimlerin varlığına işaret ettiği söylenebilir. I $\alpha \tau \rho o ́ \varsigma$ ' un dişil formu çeşitli yazıtlar, papirüslerde ve edebiyat eserlerinde, nominal bir sonek ile ortaya çıkmaktadır. ${ }^{20}$ Nitekim dişil formun en erken kullanımı Geç Helenistik dönemde Iosephus'ta karşımıza çıkmaktadır. ${ }^{21}$

Kadın hekimlerin eğitimi hakkındaki bilgiler yetersiz, var olanlar ise güvenilmezdir. Kos, Knidos, İskenderiye ve daha sonra Roma ve Pergamon'nun da dâhil olduğu bazı merkezler tıp çalışmaları açısından oldukça aktif olsalar da kadınların burada eğitim görmüș olmaları oldukça düşük bir ihtimaldir. ${ }^{22}$ Her insanın veya toplumun şifacı kadınlara ve iyileşmeye karşı tutumlarını ayrı ayrı ele almak mümkün olmadığından bir takım ortak davranışlan değerlendirebilir. Bu konuyla ilgili olarak Augustus'un İspanyol asıllı azatlısı Hyginus (MÖ 64-MS 17), Atina'da kadınların ve kölelerin tıp sanatını öğrenmesinin yasak olduğu bir dönemden ya da kadınların bazı durumlarda erkek hekimlerden eğitim alabildiğinden söz eder. Adı geçen yazar, doğruluğuna şüpheyle bakılsa da kadın hekimlerin șifa sanatlarındaki rollerini açıklamak için etiyoloji sağlayan olağandışı bir anlatıda Agnodike'nin öyküsüne yer verir. ${ }^{23}$ Buna göre, Yunan tarihinin erken dönemlerinde, Atina' da ebelerin varlığından çok önce kadınlar, erkek hekimlere sorunlarını anlatamayacak kadar iffetli olduklarından doğum sırasında ölümler oldukça yaygınmış. Agnodike adlı

\footnotetext{
${ }^{18}$ Hom. Il. 16.28; Hdt. 3.130.

${ }^{19}$ Plat. Rep. 455e; Hdt. 2.84, 3.129.

${ }^{20}$ Parker, age, s. 133.

${ }^{21}$ Ioseph. Ant. Iud. II. 206-297.

${ }^{22}$ François P Retief-Louise Cilliers, "The Healing Hand: The Role of Women in Ancient Medicine", Acta Theologica Supplementum, 7, 2005, s. 178.

${ }^{23}$ Hyg. Fab. 274, "Hagnodike".
} 
Sina, A. (2021). Yazıtlar Ișı̆ı̆ında Anadolulu Kadın Hekimler ve Ebeler. ANKARAD, 2(4), 407-424.

genç bir kadın, erkek kılığına girerek Herophilos'un yanında ebelik yapmaya başlamış. Derken, doğum yapan kadınlar arasında adı öylesine yayılmış ve ünlenmiş ki, erkek ebeler onu kadınları ayartmakla suçlamaya başlamışlar. "Areopagos Meclisi yargıçları oturumda, Agnodike’yi kınamaya başlayınca giysisini onların önünde çıkardı ve bir kadın olduğunu gösterdi. Sonra doktorlar onu daha şiddetle suçlamaya başladılar ve sonuç olarak önde gelen kadınlar Mahkemeye geldiler ve dediler ki: Siz koca değilsiniz, düşmansinız, çünkü bizim can güvenliğimizi keşfeden onu kınıyorsunuz. Sonra Atinalılar yasayı değiştirdiler, böylece özgür doğmuş kadınlar tıp sanatını öğrenebildiler." Bu öykü, özellikle 17. yüzyıldan itibaren kadın hekimlerin kendilerini erkek egemen tıp alanında savunmak zorunda kalmaları üzerine kadın hakları savunucuları tarafından sıłça anlatılmıştır. ${ }^{24}$

Kadın hekimlerin hekimlik sanatını uygulamalarına ilişkin bilgiler içeren mezar yazıtlarında, ölenlerin genellikle meslek hayatlarından ziyade, Bithynia Kios'ta bulunan Empeira'ya ait yazıtta olduğu gibi, aile ilişkilerine ve adına stel dikilmesine yol açan erdemlere daha fazla önem verilir. Bu iki örnek, tıbbi gelenek ve bunun erkek uygulayıcılardan ayrı kadın hekimlerin seslerini duymamıza yardım eden uygulamalarına ilişkin bir görüntü sağlamaktadır. Ebelerle ilgili tüm epigrafik örnekler meslek terimlerine atıfta bulunurken, kadın hekimlerin bazılarının, örneğin İstanbul'da bulunan yazıtın sahibi kadın hekim Mousa örneğindeki gibi, deneyimlerini ve mesleki başarılarını da vurguladığı görülmektedir. ${ }^{25}$ Başka bir örnekte yine Bergamalı hekim Pantheia'nın kadın hekim olarak, hekimlik sanatını uygulamadaki başarıları övülmektedir.

Bu doğrultuda, kadın şifacılar konusundaki epigrafik belgeler Hellenistik ile Geç Cumhuriyet Dönemi / Erken İmparatorluk dönemlerine aittir. Kadınlara ve iyileşmeye 1şık tutan politik ve ekonomik değișimleri kapsamayan yedi yüz yıllık (MÖ 350-MS $350 \mathrm{CE}$ ) zaman dilimini ve geniş bir coğrafya kapsadığından yalnızca Anadolu'da bulunan yazitlar örneklenecektir. Anadolu'da kadın hekimlere ilișkin sınırlı sayıdaki epigrafik örneklerden en eskisi, MÖ 2/1. yüzylla tarihlenen ve İstanbul'da bulunan bir mezar yazıtıdır.

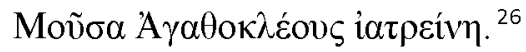

\footnotetext{
${ }^{24}$ Helen King, "Agnodike and the Profession of Medicine", PCPS NS, 32, 1986, s. 58, 69.

${ }^{25}$ Rebecca Fleming, "Women, Writing and Medicine in the Classical World", Classical Quaeterly, 57 (1), 2007, s.263.

${ }^{26}$ Nezih Firatli-Louis Robert, Les Steles Funeraires de Byzance Greco Romaine (Paris: A.

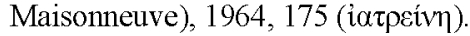


Sina, A. (2021). Yazıtlar Işı̆̆ında Anadolulu Kadın Hekimler ve Ebeler. ANKARAD, 2(4), 407-424.

[Agathokles'in kızı hekim Mousa] şeklinde geçmektedir. Bir satırdan oluşan ve baba adıyla anılmaya örnek oluşturan yazıt, mezar taşının üst kısmında yer almakta olup alt kısımda elinde kitap tutan bir kadın betimlemesi yer almaktadır.

Bithynia Kios'ta (Gemlik) bulunan ve MS 1/2. yy'a, Anadolu'da Erken Roma Dönemine tarihlenen bir yazıtta;

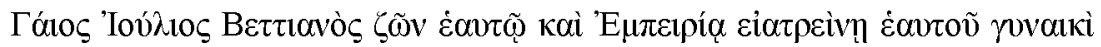

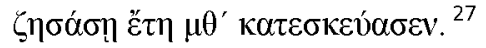

"Gaius Iulius Vettianus, sağlığında, kendisi ve 49 yıl yaşayan karısı hekim Empeiria için bu steli dikti" ifadesi yer almaktadır.

Empeiria'nın kaç yaşında öldüğü ve hekim olduğu bilgisini içeren bu yazıtta ilginç olan adının "deneyim" anlamına gelmesidir. Bu adın ileriki bir yaşta yetenekli ve başarılı bir kadın hekim olarak, yeteneklerini tanıtmak için seçilmiş olması olasıdır. Empeiria'nın uzmanlık alanına ve adının anlamına ek olarak onun erkek karakter Gaius Iulius Vettianus ile olan akrabalık ilişkisinin verilmesi de ayrıca dikkat çekicidir, zira adından yola çıkılarak bir Romalıyla evli Yunan kökenli bir kadındır Empeiria. Bu durum olanaksız olmasa da bu tarihte Kios gibi bir yerde, aristokratik sınıf mensubu olan Vettianus'un Roma vatandaşlığı kazanmış bir Yunanlı olması da olasıdır.

Galatia kenti Ankyra'da bulunan ve MS 2. yüzyıla tarihlenen yazıt şöyledir:

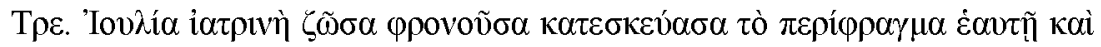

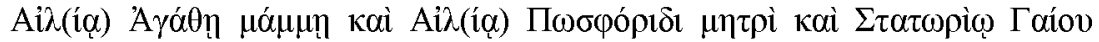

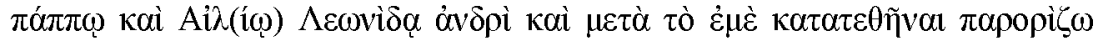

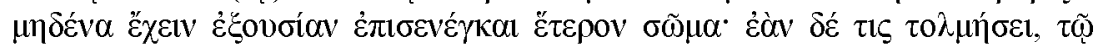

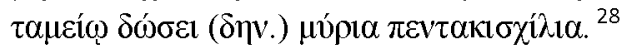

"Bir hekim olan Trebia Iulia, hayatta ve aklı bașındayken bu mezar alanını kendisi ve büyükannesi Ailia Agathe ve annesi Ailia Posphoris, büyükbabası Gaios'un oğlu Statorios ve kocası Ailios Leonidas için yaptırdı. Benden sonra başka birinin gömülmesine izin verilmeyecektir, aksi takdirde bunu yapmaya cesaret edecek kişi hazineye 15.000 denarii verecektir.

Kilikia kenti Selukia Kalykadnos olarak da bilinen Selekeia Kalyk'de (Silifke) bulunan ve MS 4. yüzyıla tarihlenen yazıt şöyledir:

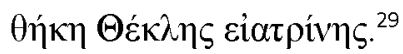

\footnotetext{
${ }^{27}$ Age, 177 (eiarpsíṿ)

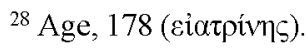

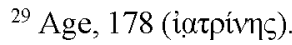


Sina, A. (2021). Yazıtlar Işı̆̆ında Anadolulu Kadın Hekimler ve Ebeler. ANKARAD, 2(4), 407-424.

"Hekim Thekla'nın mezarı" ifadesinden anlașılacağ1 üzere Thekla'nın mesleği dışında hiçbir bilgi içermez.

MS 2/3. yüzyıla tarihlenen ve Kilikia Korykos'ta bulunan bir yazıt

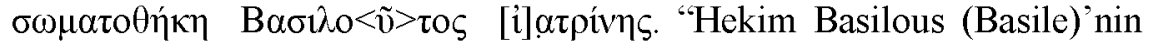
lahdi" ifadesi geçmektedir. ${ }^{30}$ Yazıtın başında ve sonunda yer alan haç işaretleri, kadın hekim Basilous'un (Basile) Hıristiyan olduğuna işaret etmektedir.

MS 3/4. yüzylla tarihlenen ve Psidia Adana'da (Karabaolu) bulunan yazıt şöyledir:

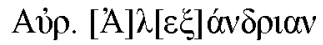

$Z[\omega \sigma] i ̣ \mu \eta v \dot{\alpha} \pi \grave{~} \dot{\pi} \pi 1-$

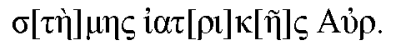

$[\Pi о \mu \pi \omega] v[\alpha]$ vò $[\varsigma$ A $] \sigma \kappa[\lambda \eta]-$

$\tau[\dot{\alpha} \delta] \eta \varsigma, \dot{o} \dot{\alpha} v[\dot{\eta} \rho] \alpha \hat{v}[\tau] \tilde{\eta} \varsigma$,

кaì

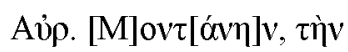

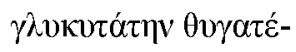

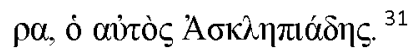

“Aurelius Pomponianus Asclepiades, hekimlik bilgisiyle tanınan kanısı Aurelia Alexandreia Zosime ve aynı zamanda son derece tatlı kızlan Aurelia Montane onuruna bu steli dikmiştir".

Adana'da, 19. yüzyılın sonlarında agorada bulunan Zosime'nin kocası tarafından kamusal alan dikilen heykelde -heykel bulunmamıştır- yer almaktadır.

Doğu Phrygia Çeşmeli Zebir'de bulunan ve MS 4/6. yüzylllara tarihlenen yazıt şöyledir:

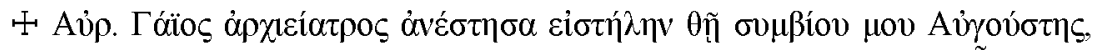

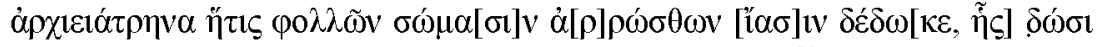

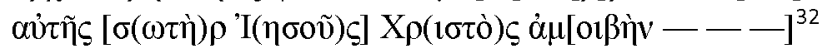

"Ben, bașhekim Aurelius Gaius, birçok hasta bedene șifa veren ve karşıllı̆̆nda kurtancı İsa Mesih'in ona vereceği (...) karım başhekim Augusta için bu steli diktim.

Bu yazıt bize aynı mesleği icra eden bir karı-koca örneği sunmaktadır.

Anadolulu kadın hekimlerden biri de Antiokhis'tir. Likya kenti Tlos agorasının güneydoğusundaki dörtgen bir kalker kaidesinde bulunan ve

\footnotetext{
${ }^{30}$ Age, 177 (iatpivms).

${ }^{31}$ Age, 175 (i $\left.\alpha \tau \rho \omega \tilde{\eta} \varsigma\right)$.

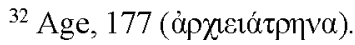


Sina, A. (2021). Yazıtlar Işığında Anadolulu Kadın Hekimler ve Ebeler. ANKARAD, 2(4), 407-424.

MÖ 1. yüzyılın başlarına tarihlenen bu yazıt, kadın șifacılarla ilgili en çok tartışılan yazıtlardan biridir.

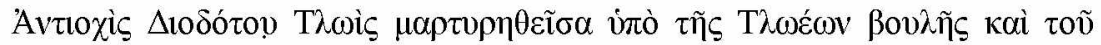

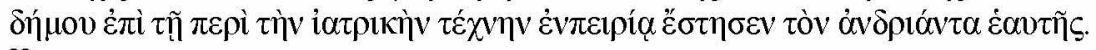
33

“Tloslu Diodotos'un kızı Antiokhis'e, Tlos kenti Meclisi ve halkı, hekimlik sanatındaki başarısını tanıtması amacıyla kendi heykelini dikmesine karar vermiştir."

Diğer yandan Antiokhis'in heykelinin kentin agorasına yerleștirilmesi durumu, aile ilişkileri bağlamında kadın hekimin babasının adıyla anılması ve yetenekli şifacı kadınların toplumsal statülerinin araştırılıp incelenmesinde son derece güzel bir örnek sunmaktadır. Antiokhis, doğrudan i $\alpha \tau \rho i v \eta$ (kadın hekim) unvanıyla adlandırmak yerine, yalnızca tıbbi yeteneğinden dolayı övgüler topladığının ifade edilmesi dikkat

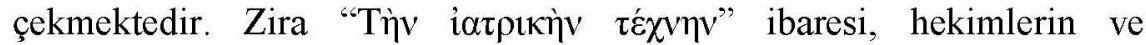
konseydeki kişiler tarafindan atanan tıbbi görevler yapan kişilerin niteliklerini tanımlamak için kullanılır. ${ }^{34}$ Yazıtta dikkati çeken bir diğer nokta da Antiokhis'in babası Tloslu Diodotos'a atıfta bulunarak baba-kız hekim örneği olușturmasıdır. Kentinden resmi onur alan Antiokhis'e verilen böylesine büyük bir ödül, bu kadın hekimin şifa sanatına genel atıf olup, olasılıkla yalnızca kadın hastalarla sınırlı olmayan, aksine kent çapında tıbbi hizmet verdiğine ișaret etmektedir. Baba ve kızın hekimlik mesleğindeki başarılarının kanıtı, MS 1. yüzyılda yaşamış ve Roma ordusunda görev Anazarboslu (Adana Anazarva) yapan hekim Dioskurides'in, De Materia Medica (Sağaltıcı Maddeler Üzerine) başlıklı eserinde Tloslu Diodotos'tan söz etmesinde de görülebilir. ${ }^{35}$

Ayrica Tloslu Antiokhis, olasılıkla Galenos'un romatizma ve siyatik ağrılarına karşı bir ilaç bulmuş olduğu için övgüyle söz ettiği kişidir. ${ }^{36}$

MS 2. ikinci yüzyıla tarihlenen ve Bergama'da bulunan diğer bir yazıt ise kocasından hekim Pantheia/Panthia'ya övgü dolu ve samimi bir vedayı konu almaktadır.

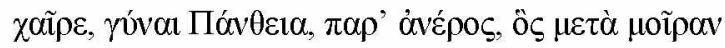

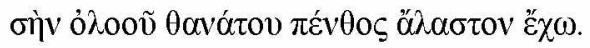

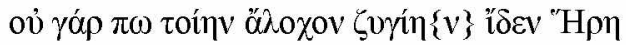

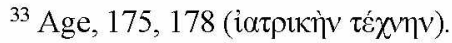

${ }^{34}$ Holt Parker, "Galen and the Girls: Sources for Women Medical Writers Revisited", The Classical Quarterly, 62(1), 2012, s. 359-386. 374.

${ }^{35}$ Irving, age, s. 104.

${ }^{36}$ Galen. XIII $250,341 \mathrm{~K}$.
} 
Sina, A. (2021). Yazıtlar Ișığında Anadolulu Kadın Hekimler ve Ebeler. ANKARAD, 2(4), 407-424.

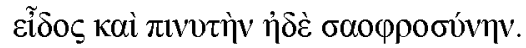

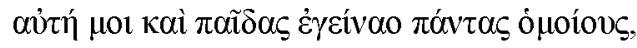

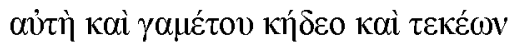

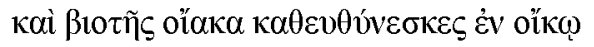

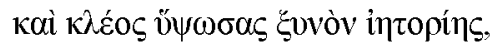

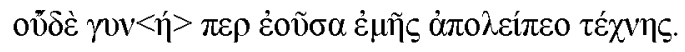

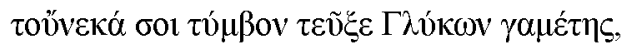

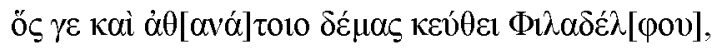

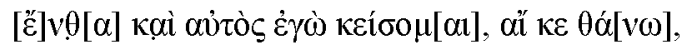

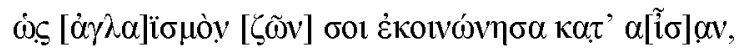

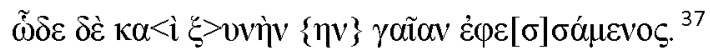

'Elveda sana, karım Pantheia'ya kocandan. Sen gittiğinden bu yana, acımasız ölümünden dolayı hala keder içindeyim. Evlilik tannıçası Hera, senin kadar güzel, bilge, iffetli bir eş görmemişti. Hepsi bana benzeyen çocuklar verdin bana; damat ve çocuklarına değer veriyordun, evimizdeki yaşamın dümenini sen yönettin ve șifa konusunda ortak şöhretimizi yükselttin- sen bir kadın olmana rağmen yeteneklerinle benden geri kalmadın. Bunun farkında olan damadın Glykon senin için bu mezarı inşa etti. Ayrıca buraya babam ölümsüz Philadelphos'u da gömdüm ve öldüğ̈̈mde ben de burada yatacağım; yașarken seninle şöhretimi ve kaderimi paylaștım, bu yüzden paylaștı̆̆ımız toprağa yatayım ben de."

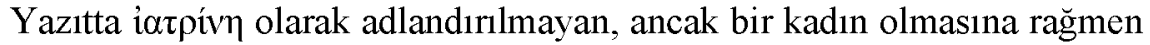
şifa sanatında kocasından geri kalmadığı yönüyle övülen ise gerçekte hekim Pantheia değil, kocadır.

Neoclaudiopolis'te (Vezirköprü) bulunan ve MS 2/3. yüzyıla tarihlenen bir diğer yazıt şöyledir:

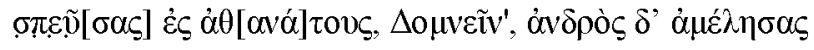

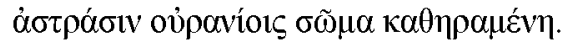

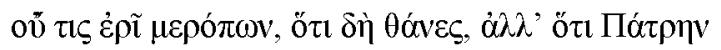

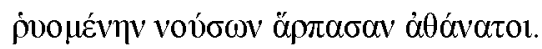

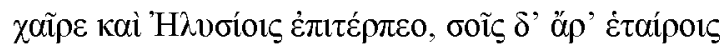

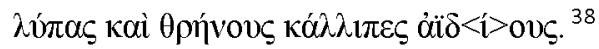

"Ölümsüzlerle olmak için aceleyle ayrıldın unutup kocanı Domnina. Kutsal yıldızlara yükseldi bedenin. Ölümlülerin hiçbiri öldügünüü söylemeyecek, fakat ölümsüzler seni benden aldı, sen vatanım hastalıktan kurtardığın için. Elveda, mutlu ol Elysium Çayırlarında. Fakat arkadaşların için geride acı ve ebedi ağıtlar biraktın".

\footnotetext{
${ }^{37}$ Pleket, age, s.32.

${ }^{38}$ Firatli and Robert 1964, 175vd.; Pleket 1969, s.38.
} 
Sina, A. (2021). Yazıtlar Işı̆̆ında Anadolulu Kadın Hekimler ve Ebeler. ANKARAD, 2(4), 407-424.

Çalışma konumuz yalnızca Anadolu ile sınırlandırılmakla birlikte hekimlik sanatıyla uğrașan kadınlara ait mezar yazıtlarının bütünü göz önüne alındığında, pek çok tanıdık adla karşılaşırız. Vivian Irving, Kleopatra, Thekla, Sotira, Empeiria, Maia ve Mousa örneğindeki kadın hekimlerin yaptıklan meslekle yakından ilgisi olan bu adlan sonradan almış olabileceklerini ileri sürer. ${ }^{39} \mathrm{Bu}$ adlardan Kleopatra "baba" ve "ün" sözcüklerinin birleşmesinden, Thekla, "tanrı" ve "zafer" sözcüklerinin birleşmesinden, Sotira "kadın kurtanıc", Maia ise Yunanca "anne anlamına gelen mêtēr sözcügüüün bebek diliyle söylenmesinden, Empeira "deneyim" ve Mousa ise "bellek, zekâ" anlamlanna gelmektedir. Hekim ya da ebe kadınların adlarının taşıdığı anlamlar, onların şifacı olduklarını kanıtlar ve şifa sanatında uzmanlaşan kadınların ilham verici çağnışımlar olarak bu adları seçmiș olmaları ise toplumda saygınlık kazanmaya yönelik olabilir.

\section{Ebeler}

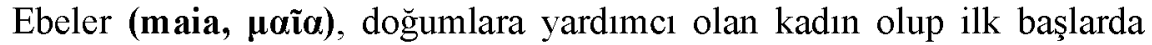
yalnızca diğer ebelerden basit ve temel bir eğitim alıyorlardı. Annelerin kızlarına öğreterek bunu bir aile geleneği haline getirdiği ve kölelerin tecrübeli ebelerden görerek işi öğrendiği durumlara sıkça rastlanır. Erken yaşta başlayan bu "ev içi eğitim", Helenistik dönemden (MÖ 4-3. yüzy1l) itibaren obstetrik ve jinekolojik çalışmalarla da desteklenmiş̦tir. Bu çalışmalara örnek olarak Herophilos'un ebeler için yazdığı el kitabı Maieutikon, Soranus'un ebeler için yazdığı bir diğer el kitabı ve Galenos'un rahmin anatomisi üzerine yazdığı eser gösterilebilir. Bununla birlikte hem Soranus hem de Galenos, diğer erkek yazarlar gibi, ebelerin mutlaka bir erkek hekim gözetiminde çalışmaları gerektiğini ileri sürmüşlerdi. ${ }^{40}$

Moĩ $\alpha$ terimi ebeler için epigrafik kanıtları tespit etmeyi zorlaştıran çeşitli anlam ve çağrışımlarla da ilişkilidir. Sözcüğün "ebe" anlamı dışında "yaşlı kadın", "sütanne", "koruyucu anne" veya "hemşire" ya da bazen "büyükanne" anlamları bulunmaktadır. Örneğin, Odysseia destanında 19.482, Odysseus'un Eurykleia için kullanılan maia terimi "sütanne" anlamindadir.

\footnotetext{
${ }^{39}$ Irving, age, s. 159.

${ }^{40}$ Vivian Nutton, Ancient Medicine, Second Edition, ed. L. Taub (Series of Antiquity; London: Routledge), 2013, s.201.
} 
Sina, A. (2021). Yazıtlar Işı̆̆ında Anadolulu Kadın Hekimler ve Ebeler. ANKARAD, 2(4), 407-424.

Ebeler hakkında Roma İmparatorluk Dönemi Anadolu'sunda Korykos'ta (Mersin) bulunan bir mezar yazıtı şöyledir:

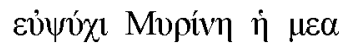

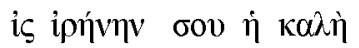

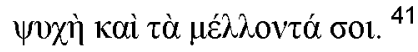

"Müsterih ol ebe Myrine! Güzel ruhun huzura ve senin kaderinde olan șeylere gidiyor."

Son olarak Kilikia Korykos'tan hem ebe hem de hekim olan Stephanis ile ilgili yazıt şöyledir:

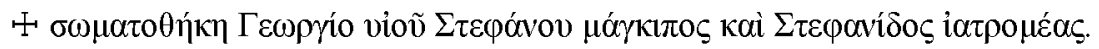
42

"Stephanos'un oğlu (magkipos) müteahhit Georgios'un ve ebe-hekim Stephanis' in lahitleri."

Ebelerle ilgili bu iki mezar taşı yazıtı, onları meslekleri dışında bir bilgi sunmazlar.

T1p eğitimi dönemden döneme, bölgeden bölgeye ve kişiden kişiye büyük farklılıklar göstermekle birlikte, erkeklerinkine benzer olarak teoriden ziyade pratik odaklı bir eğitim aldıklarını ve bunun yanı sıra tecrübeli erkek hekimlerin yanında yardımcılık yaptıklarını çıkarım sayabiliriz. Kadınların tıp mesleğine katılımına ilişkin kanıtların iki türe ayrılabileceği ileri sürülür: mevcut erkek hekimlerin metinlerinde referans gösterilen kadın yazarlar ve tıp konusunda hem metinleri hem de hekimlik sanatındaki uygulamaları günümüze ulaşan yazarlar. ${ }^{43}$ Yazar olarak değil de doğrudan hastaları tedavi eden kadın hekimlerin eğitiminin ise bazı durumlarda özellikle en nesnel kanıtlar sunan mezar yazıtlarından anlaşılacağı üzere, tıbbi mesleklerin bir aile geleneği haline gelmesiyle ev içi eğitim de önemli yer tutmaktadır. Bunun bir örneği, kendisi de meşhur bir hekim olan babasından eğitim ve destek gören Tloslu Antiokhis'tir. ${ }^{44}$ Diğer bir örnek ise kendisi de bir hekimin kızı olan Bergamalı Pantheia ve onun mezar taşı için emsalsiz bir yazıt oluşturan kocası örneğinde karşımıza çıkan tıp alanında hizmet veren çiftlerin varlığıdır ${ }^{45} \mathrm{Bu}$ kadınlar, eşlerinden ya da

\footnotetext{
${ }^{41}$ Firatli and Robert 1964, $176(\mu \varepsilon \alpha)$.

42 Age, 177 (no.89).

${ }^{43}$ Flemming, Rebecca (2007), "Women, Writing and Medicine in the Classical World", Classical Quarterly, 57 (1), 257-79. 263.

${ }^{44}$ Firatli, Nezih- Robert, age, 175, 178

${ }^{45}$ Pleket, Henri Willy (1969), Epigraphica Vol. II: Texts on the Social History of the Greek World (Leiden: Brill), 1969, s. 32; Irving, Jennifer C. (2015) The Greek Eprgraphic Evidence For Healer Women In The Greek World. Basllmamıș Doktora Tezi. s.80-81.
} 
Sina, A. (2021). Yazıtlar Ișı̆ı̆ında Anadolulu Kadın Hekimler ve Ebeler. ANKARAD, 2(4), 407-424.

babalarından eğitim almanın yanı sıra o dönemde ebeler için yazılan el kitaplarından da faydalanabiliyorlardı. Bu bağlamda, MÖ 2-1. yüzyılda yaşamış bir iatrine olan Mousa adlı bir kadın hekimin mezar taşındaki kabartmalarda, öğrenimini simgeleyecek bir biçimde elinde kâğıt rulolarıyla betimlendiğine rastlanz. Genel itibariyle, kadın hekimlerin aldığı eğitimin tıpkı erkek meslektaşlarınınki gibi pratik odaklı olduğunu ve tıbbi becerilerin bir okul veya kült yoluyla değil de ebeveynden, eșten ya da yanında çalışılan bir uzmandan edinildiğini söyleyebiliriz.

\section{Sonuç}

Helenistik ve Roma imparatorluk dönemlerinde kadın tıp uygulayıcılarına genel referanslar ve temsiller, edebi kültürle de ilişkidedir. Toplumsal yapıların sınırlı bir görüntüsünü verse de kadın hekim ve ebeler hakkında Anadolu'dan günümüze ulaşan epigrafik materyallerden özellikle mezar yazıtları, karı-kocaların, babaların ve kızların aynı mesleklere katıldığını göstermiş̧ir. Ayrıca aileler, erkeklere özgü olduğu düşünülen hekimlik mesleğinin kızlarına ya da eșlerine geçebildiğine de işaret etmiştir. Her kadın hekim ne yalnızca gebelik ve doğumla ilgili konularda ne de yalnızca kadınları ve küçük çocukları tedavi ederdi. Başlangıçta kadın hekimler kadınları tedavi etmiş olsa erkekleri de tedavi etmişlerdir. Bu durum özellikle MS 1 ve 2. yüzyıllarda Anadolu'dan bulunan yazıtlar, belirli bir geçmişi olan bir kadının, hekimlik mesleğinde Antiokhis ve Domnina'nın mezar yazıtlarında gördüğümüz gibi, mesleklerinde uzman olduklanın ve toplumlarında anayurtlarını (hastalıklardan) korudukları için büyük ün kazandıklarını, göstermektedir. ${ }^{46}$ Bu değerli kadın hekimlerin ölümlerinin yalnızca kocaları/aileleri için değil, memleketleri için de kayıp olduğunu ifade edilir. Panthia'nın mezar yazıtı ise toplumu içinde bir şifacı olarak "kurtarıcı" ününü kazanması, her ikisi de hekim olan kocası ve kendi babasına denk bir hekim olduğunu kanıtlar. Ayrıca yazıtlar, ailesel meslek etkileşimlerini sergileyerek, ebeveynlerinin çocuklanını kendi mesleklerinde eğitmenin en iyi kanıtlanmış bilgi ve beceri aktarma biçimi olduğunu da göstermiştir. Evdeki şifa sorumluluklarına ilişkin kanıtların yanında kadın hekimler, babalarının veya annelerinin öğrencileri olmalarının yanı sıra aslında süregelen bir geleneğe de tanıklık ederler. Geç Klasik ve Helenistik dönemler şifacı kadınlarla ilgili olarak erkek şifacılann eğitimiyle aynı anda gelişen bir eğitim aldıklanını göstermiştir. Ayrıca da yazıtlarda kullanılan terminoloji şifacı kadınların, mesleki rollerinde cinsiyet ayrımcılığına uğramadığını da işaret etmektedir. Söz konusu dönemler, toplumda kadın hekim ve ebe özelinde, kadınlara yönelik tutumların değiştiğini ve genel olarak toplumun sayg1 duyulan

\footnotetext{
${ }^{46}$ Retief-Cilliers, age, 2005, s. 176; Irving age, s.214.
} 
Sina, A. (2021). Yazıtlar Işı̆̆ında Anadolulu Kadın Hekimler ve Ebeler. ANKARAD, 2(4), 407-424.

üyeleri olarak kabul gördüklerini göstermiștir. Kadın hekimlerin, erkek mesleği yaptıkları düşünülse bile, toplumdan topluma değişen genel kabul seviyeleri mutlaka vardı, ama gerek kanıtların niteliği gerekse sayılarının az olmasından dolayı, onlara karşı yapılan muhalefeti gösteren hiçbir kayıt yoktur. Anadolu'da bulunan yazıtlardan, saygınlık açısından, şifacı kadınların toplumlarında olumlu karşılandığını söyleyebiliriz, ancak şüphesiz coğrafi alan ve zamana bağlı olarak bu tutumun değiștiği de bir gerçektir. Kadın hekim ve ebelere ilişkin mezar yazıtlarının bize sundukları doğrultusunda, söz konusu dönemlerde çok daha fazla șifacı kadının onurlandırıldığını düşünmek yanlış olmayacaktır.

\section{Kaynakça}

\section{Antik Kaynaklar}

Diog.Laert. V Aristoteles =Diogenes Laertios, Ünlü Filozoflarn Yaşamlart ve Öğretileri (Çev. C. Şentuna). İstanbul: Yapı Kredi Yayınları 2015.

Gal. Nat. Fac. $=$ Galenos, Galen, On the Natural Faculties. trans. A.J. Brock, Loeb Classical Library (London, Harvard University Press, 1963).

Hdt.=Herodotos, Herodot Tarihi (Çev. M. Ökmen) İstanbul: Remzi Kitabevi 2004.

Hom. Il $=$ Homeros, İlyada (Çev. A. Erhat- A. Kadir) İstanbul: Can yaymları 1998.

Hyg.Fab.=Hyginus, Fabulae: M.A. Grant (ed.), The Myths of Hyginus (Lawrence, University of Kansas Publications, 1960).

Ioseph. Ant.Iud.=Iosephus, Antiquitates Iudaicae. Șurada: Mason, Steve (2001), Life of Josephus, Col. 9 of Flavius Josephus: Translation and Commentary (Leiden: Brill).

Iven.=Iuvenalis, Yergiler-Saturae (Çev. Ç. Dürüşken- Alova) İstanbul: Kültür Yayınları 2003.

Mart.=Martialis. Epigramlar (Çev. G. Varinlioğlu) İstanbul: Yapı Kredi Yayınları 2005.

Plat. Rep.=Platon, Devlet (Çev. S. Eyüboğlu- M. A. Cimcoz) İstanbul: Remzi Kitabevi 1995.

Plat. Theait.=Platon, Theaitetos Şurada: Diyaloglar (Çev. T. Aktürel) İstanbul: Remzi Kitabevi 1998.

Plin. $N H=$ Plinius Caecilius Secundus, Pliny, Natural History with an English Translation by W. H. S. Jones. Cambridge: Harvard University 2005.

Soran. Gynec=Soranus, Gynecology. Owsei Temkin (ed.), Soranus' Gynecology, Baltimore, Johns Hopkins Press, 1956.

\section{Modern Kaynaklar}

FIRATLI, Nezih-ROBERT, Louis (1964), Les Steles Funeraires de Byzance GrecoRomaine (Paris: A. Maisonneuve).

FLEMMING, Rebecca (2007), 'Women, Writing and Medicine in the Classical World', Classical Quarterly, 57 (1), 2007, s. 257-279.

IRVING, Jennifer C. (2015) The Greek Epigraphic Evidence For Healer Women In The Greek World. Basilmamıs Doktora Tezi.

JACKSON, Ralph (1999) Roma Imparatorluğu'nda Doktorlar ve Hastalıklar (Çev. Ş. Mumcu) İstanbul, Homer Kitabevi. 
Sina, A. (2021). Yazıtlar Işı̆̆ında Anadolulu Kadın Hekimler ve Ebeler. ANKARAD, 2(4), 407-424.

KING, Helen (1986), "Agnodike and the Profession of Medicine", PCPS NS, 32, 53-77.

NUTTON, Vivian (2013), Ancient Medicine, Second Edition, ed. L. Taub (Series of Antiquity; London: Routledge)

PARKER, Holt (1997), "Women Doctors in Greece, Rome, and the Byzantine Empire", in Lilian R. Furst (ed.), Women Healers and Physicians: Climbing a Long Hill (Lexington: University Press of Kentucky), 131-50.

PARKER, Holt (2012), "Galen and the Girls: Sources for Women Medical Writers Revisited", Classical Quarterly, 62(1), 359-386.

PLEKET, Henri Willy (1969), Epigraphica Vol. II: Texts on the Social History of the Greek World (Leiden: Brill).

POMEROY, Sarah B. (1978), "Plato and the Female Physician (Republic 454d2)", The American Journal of Philology, 99 (4), 496-500.

RETIEF, François P.-CILLIERS, Louise (2005), "The Healing Hand: The Role of Women in Ancient Medicine", Acta Theologica Supplementum, 7, 165-188.

ROSENTHAL, F. (1956) "An ancient commentary on the Hippocratic oath", Bulletin of the History of Medicine, 30: 52-87. 